\title{
Relation of parental age to rigidity in Huntington's disease
}

\author{
C. J. BRACKENRIDGE \\ From the Department of Psychiatry, University of Melbourne, Victoria, Australia
}

\begin{abstract}
Summary. The birth ranks and parental ages at birth of subjects affected with Huntington's disease were ascertained from the literature and examined in relation to the neurological sign displayed (muscular rigidity or choreo-athetosis). With respect to the sex of the affected parent, the percentage of rigid cases was found to decrease linearly with advancing paternal age and to increase linearly with advancing maternal age. In contrast, no significant relation was found for birth rank or for age of the unaffected parent.

The results could be explained in terms of the somatic gene-mutation theory of Burch by invoking a 'switching mechanism' which converts a predisposing autosomal allele for rigidity in the germ cell of affected fathers into one which is expressed as chorea. The converse mechanism is postulated to occur in affected mothers. Calculation showed that the hypothetical mutation rates were of the same magnitude in affected parents of each sex.
\end{abstract}

In a previous study (Brackenridge, 1973), it was shown that the choreic and rigid forms of Huntington's disease each possess a characteristic distribution of the ages at which symptoms first appear. For persons with the rigid form a strong inverse relationship was found between the proportion with affected fathers and onset age. The effect was much weaker when choreoathetosis was the principal sign. An understanding of the parental factors which affect the onset-age and symptomatology of the disorder is clearly important; in particular, the reason for the high proportion of rigid cases with affected fathers needs to be explained.

Two recent publications have suggested that parental age at conception may exert effects on a child bearing the deleterious gene. Jones (1973) presented data consistent with the idea of a reduced sex-ratio of children born to affected women in the years just preceding onset of symptoms. Burch (1973) has raised the possibility that the predominance of paternal transmission of the rigid form of Huntington's disease may arise from allelic conversion (such as a switch in transcription from one strand of DNA to its antiparallel strand) induced in parental germ-cells by an autoaggressive attack.

Received 16 October 1973.
'When a large enough series of rigid-akinetic cases has been collected, it might be worth analysing the data for the possible influence of paternal or maternal age at conception. Indeed, all clinical forms of the disease might usefully be investigated from this viewpoint' (Burch, 1973). The present study represents such an attempt.

\section{Material and Methods}

Subjects affected with Huntington's disease were ascertained from the world literature where the presence or absence of muscular rigidity together with the sex and age of the affected parent at their birth was known. The sources were those cited in Appendix III of Brackenridge (1972b).

The null hypotheses adopted were that the proportion of rigid subjects was independent of birth rank and parental ages. Because of their mutual correlation, separating the effects of birth rank and parental ages poses a familiar problem. In the context of Huntington's disease, the fact that one parent bears the abnormal gene introduces a further complication. The existence of five variables (birth rank and ages of affected and unaffected fathers and mothers) makes resolution difficult; as a first step their individual effects were examined using a simple regression model. Variables were divided into groups of similar size, and the percentages of rigid offspring in each were regressed on their means. 


\section{Results}

The null hypothesis that the proportion of rigid subjects was independent of birth rank was tested on data obtained from 676 ascertained cases, 551 being choreic and 125 showing rigid features. The data are set out in Table I and Fig. 1 shows the regression line obtained for birth ranks 1 to 5 and 6 or higher. The estimate and standard error of the regression coefficient, $0.467 \pm 0.457$, demonstrates that the null hypothesis is upheld. Division of material according to the sex of the affected parent yielded the same conclusion, the slopes being 0.979 \pm 0.796 for cases of paternal transmission and $-0.0631 \pm 0.483$ for cases of maternal transmission.

The relationships between neurological sign and parental ages at birth of the cases were next examined. Analysis of the 172 subjects of paternal

TABLE I

DISTRIBUTIONS OF CLINICAL FORMS IN RELATION TO BIRTH RANK

\begin{tabular}{c|c|c|c}
\hline IBirth Rank & Chorea & Rigidity & Total \\
\hline 1 & 174 & 38 & 212 \\
2 & 101 & 25 & 126 \\
3 & 76 & 15 & 91 \\
4 & 67 & 12 & 79 \\
5 & 43 & 10 & 53 \\
6 & 32 & 11 & 43 \\
7 & 20 & 8 & 28 \\
8 & 17 & 4 & 21 \\
9 & 10 & 0 & 10 \\
10 & 5 & 1 & 6 \\
11 & 5 & 0 & 5 \\
12 & 1 & 0 & 1 \\
14 & 0 & 1 & 1 \\
\hline
\end{tabular}

descent shown in Table II produced a significant negative linear regression of percentage with rigidity on age of affected father (Fig. 2). On the other hand, analysis of the 124 subjects of maternal descent shown in Table III produced a significant positive linear regression of percentage with rigidity on age of affected mother (Fig. 2). The coefficients obtained were $-0.824 \pm 0.0387 \quad(P<0.004)$ for paternal cases and $0.871 \pm 0.0306(P<0.002)$ for maternal cases. There was an obvious difference between their magnitudes.

These results are not conclusive as they stand, since the apparent converse age-effects of affected parents could reflect the primary influence of unaffected parental ages. Tables IV and V present the material in relation to the normal parent. Fig. 3 demonstrates that the regression line for unaffected paternal cases mimics that for affected maternal cases while the regression line for unaffected maternal cases resembles that for affected paternal cases. It was not possible to demonstrate

TABLE II

DISTRIBUTIONS OF CLINICAL FORMS IN RELATION TO AGES OF AFFECTED FATHERS

\begin{tabular}{c|c|c|c}
\hline \multirow{2}{*}{$\begin{array}{c}\text { Paternal Age-Range } \\
\text { at Birth of Offspring }\end{array}$} & \multicolumn{2}{|c|}{ Number of Affected Offspring } \\
\cline { 2 - 4 } & Choreic & Rigid & Total \\
\hline 27 or less & 31 & 15 & 46 \\
$28-32$ & 33 & 13 & 46 \\
$33-37$ & 29 & 9 & 38 \\
38 or more & 34 & 8 & 42 \\
\hline
\end{tabular}

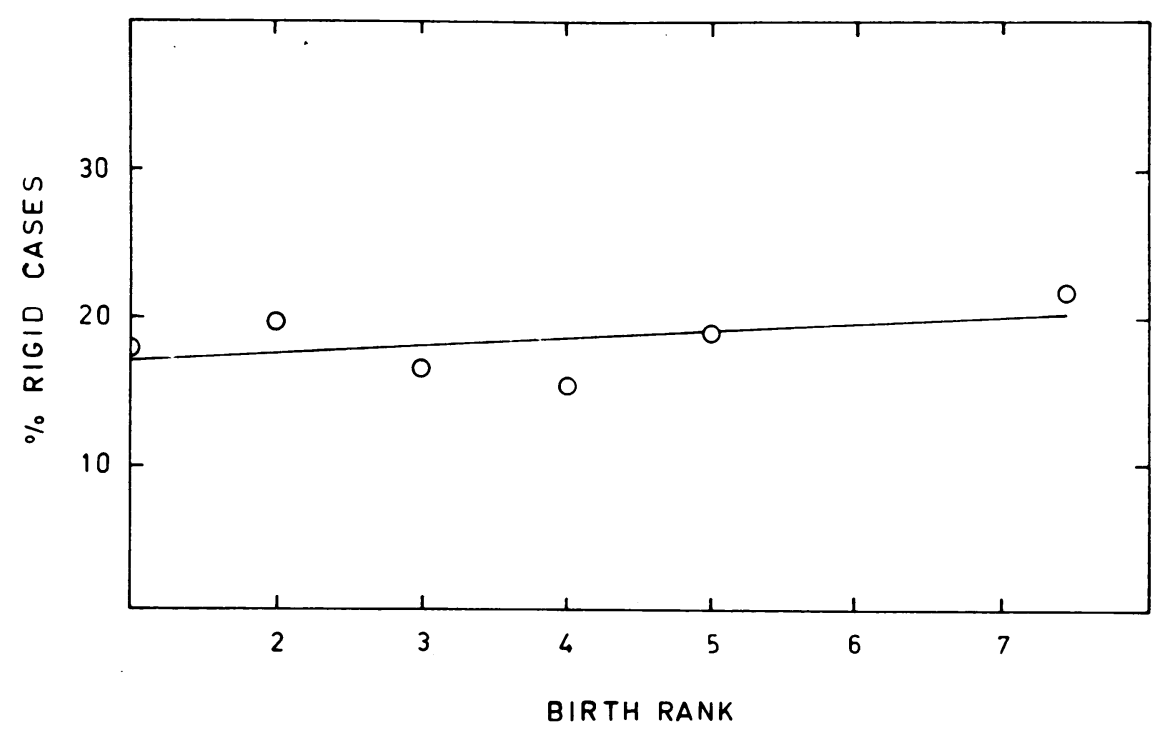

FIG. 1. Linear regression of percentage of rigid cases on birth rank. 


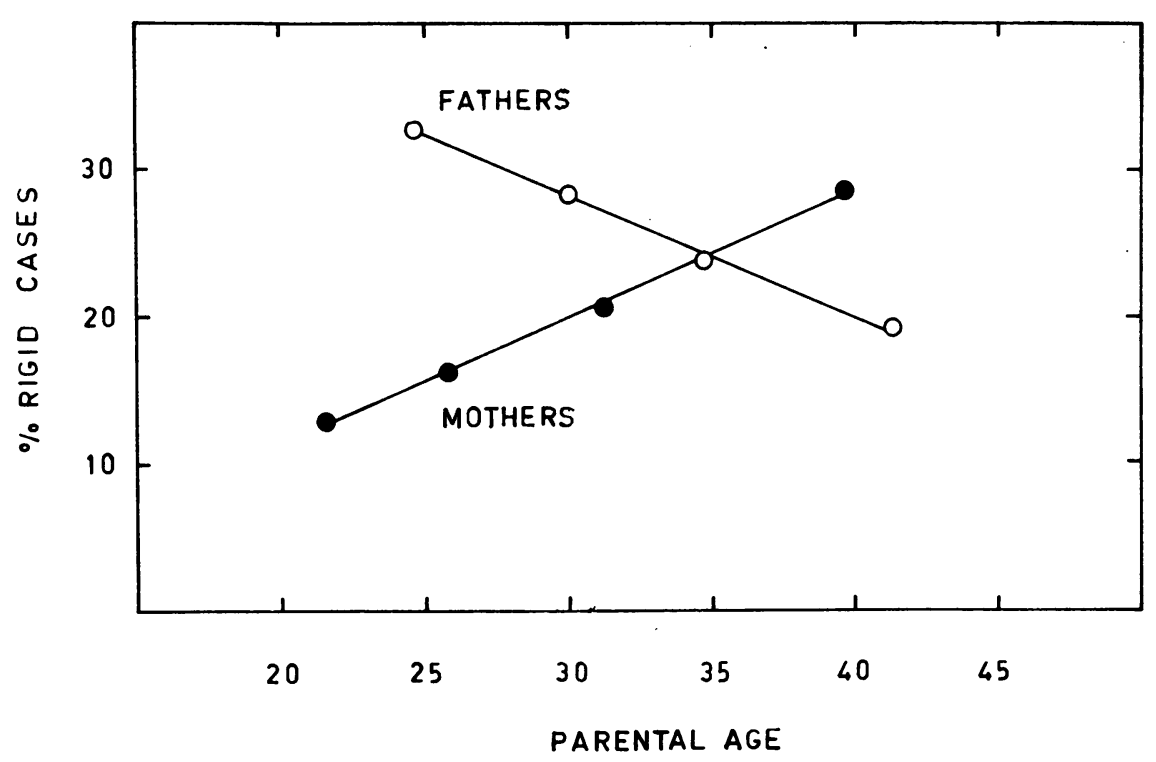

FIG. 2. Linear regression of percentage of rigid cases on affected parental ages at their birth.

the differences of the unaffected parental slopes from zero. The regression coefficients were $1 \cdot 199$ $\pm 0.324(P>0.05)$ for persons with normal fathers and $-0.907 \pm 0.0982(P>0.05)$ for persons with normal mothers. As in the case of the affected parents, these slopes differed significantly from each other $(F=37.39$ with 1,2 df; $P<0.03)$. No dif- ference between the slopes was found for subjects with unaffected mothers and affected fathers $(F=$ 0.83 with $1,3 \mathrm{df} ; P>0.4$ ) or for those with unaffected fathers and affected mothers $(F=1.59$ with $1,3$ df $;>0.3)$. Further comparisons were made between slopes for cases with affected and normal fathers $(F=54.61$ with $1,3 \mathrm{df} ; P<0.01)$ and for

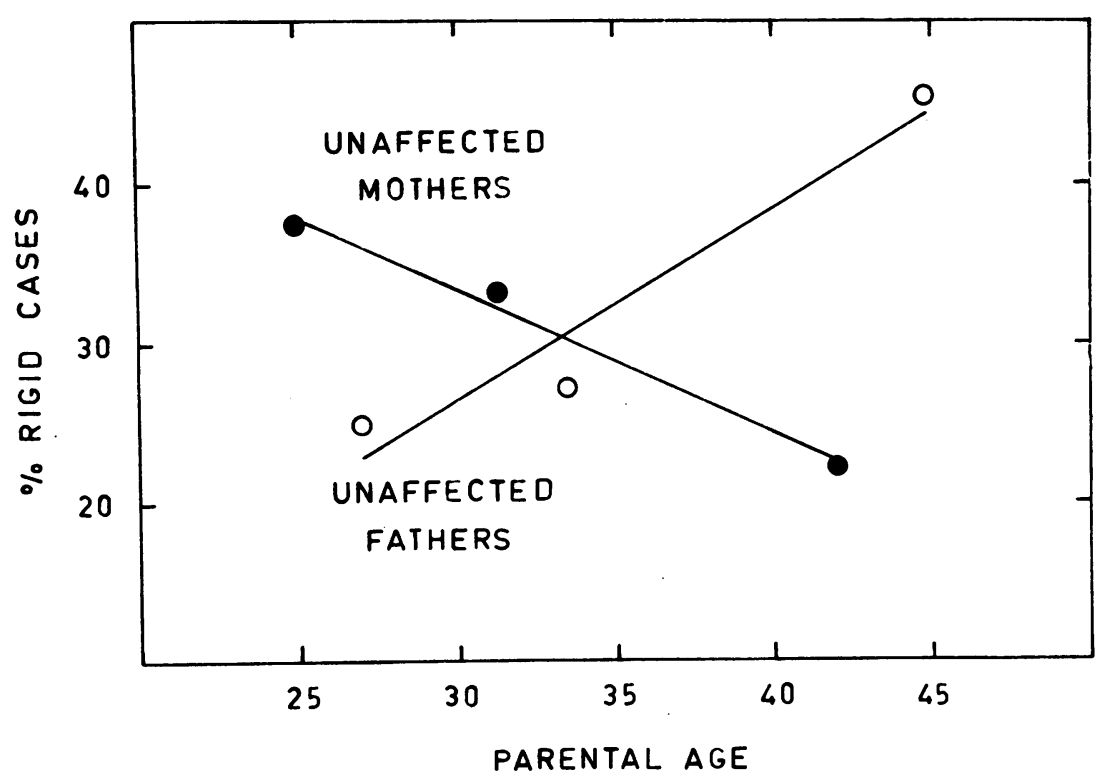

FIG. 3. Linear regressions of percentage of rigid cases on unaffected parental ages at their birth. 
TABLE III

DISTRIBUTIONS OF CLINICAL FORMS IN RELATION TO AGES OF AFFECTED MOTHERS

\begin{tabular}{c|c|c|c}
\hline $\begin{array}{c}\text { Maternal Age-Range } \\
\text { at Birth of Offspring }\end{array}$ & \multicolumn{2}{|c|}{ Number of Affected Offspring } \\
\cline { 2 - 4 } & Choreic & Rigid & Total \\
\hline 24 or less & 27 & 4 & 31 \\
$25-28$ & 26 & 5 & 31 \\
$29-34$ & 27 & 7 & 34 \\
35 or more & 20 & 8 & 28 \\
\hline
\end{tabular}

TABLE IV

DISTRIBUTIONS OF CLINICAL FORMS IN RELATION TO AGES OF NORMAL FATHERS

\begin{tabular}{c|c|c|c}
\hline \multirow{2}{*}{$\begin{array}{c}\text { Paternal Age-range } \\
\text { at Birth of Offspring }\end{array}$} & \multicolumn{2}{|c|}{ Number of Affected Offspring } \\
\cline { 2 - 4 } & Choreic & Rigid & Total \\
\hline 29 or less & 6 & 2 & 8 \\
$30-38$ & 8 & 3 & 11 \\
39 or more & 6 & 5 & 11 \\
\hline
\end{tabular}

TABLE V

DISTRIBUTIONS OF CLINICAL FORMS IN RELATION TO AGES OF NORMAL MOTHERS

\begin{tabular}{c|c|c|c}
\hline \multirow{2}{*}{$\begin{array}{c}\text { Maternal Age-Range } \\
\text { at Birth of Offspring }\end{array}$} & \multicolumn{3}{|c}{ Number of Affected Offspring } \\
\cline { 2 - 4 } & Choreic & Rigid & Total \\
\hline 28 or less & 5 & 3 & 8 \\
$29-34$ & 6 & 3 & 9 \\
35 or more & 7 & 2 & 9 \\
\hline
\end{tabular}

cases with affected and normal mothers $(F=436$. 76 with $1,3 \mathrm{df} ; \mathrm{P}<0.001$ ).

When all the analyses described in this section were repeated for male and female subjects, no differences between the sexes were found.

\section{Discussion}

The results demonstrate conclusively that the proportion of subjects with Huntington's disease displaying muscular rigidity during the course of their illness is unrelated to their birth rank. On the other hand, there is strong evidence that parental ages at the birth of affected cases play a significant role in relation to rigidity. Somewhat less clear is whether it is the affected or normal parent who exerts the primary influence. The inference that it is the affected person is supported by the findings that only cases descended from affected parents showed significant regression coefficients. It follows from this argument that the almost significant slopes derived from normal parents are due to the correlation between paternal and maternal ages. It might fairly be objected, however, that the data available or analysis of unaffected parental ages (56 cases) are appreciably less than for affected parental ages (296 cases).

There are grounds for reaching a verdict on the issue from external evidence. Byers and Dodge (1967) reported the occurrence of two rigid cases of the disorder in their family B; they were offspring of an affected man by two normal wives. Recalling the low prevalence of rigid cases-12 to $14 \%$ according to Bittenbender and Quadfasel (1962) and $18.5 \%$ in the present study-the probability that the sign was attributable to the unaffected mothers is low. Of less direct relevance is the conclusion that allelic forms of the main Huntington gene play little or no part in determining age at onset of symptoms (Brackenridge, 1972a). Because rigid patients have a much earlier mean onset age than choreic patients (Bittenbender and Quadfasel, 1962; Brackenridge, 1973), it could be argued that the normal parent exerts no obvious effect on the neurological features of affected offspring.

Any attempt to interpret the present results must take into account the discordant neurological signs shown by monozygotic twin sisters described by Oepen (1973). Unless Mendelian laws are abrogated, chorea or rigidity must either be environmentally induced or non-genetic factors can overcome hereditary predisposition. Brackenridge (1972c) has argued that the predominant neurological sign is basically related to the onset age of the subject rather than the parent and suggested that the underlying pathology was sufficient to account for the neurological features of a given case.

It is difficult to conceive of an environmental factor correlated positively with maternal age and negatively with paternal age. On the other hand, sex-linked or sex-limited modifying genes can be discounted by the similarity of the results obtained on male and female cases. It would seem that the theory of 'autoaggressive disease' put forward by Burch (1968) can explain most of the present results.

Burch (1973) has suggested that rigidity requires the predisposing autosomal allele $a_{r}+$ in homozygous form $\left(a_{r+} / a_{r+}\right)$ in addition to the main Huntington gene. He elaborated two hypotheses which are not mutually exclusive: (1) in an affected father, a 'switching mechanism' sometimes converts an $a_{r}$ - allele in his germ cells to the $a_{r}+$ allele, and (2) in an affected mother, a similar 'switching mechanism' sometimes operates in reverse to convert an $a_{r}+$ allele in her germ cells to an $a_{r}$ - allele. Burch points out that although hypotheses (1) and (2) do not necessarily imply a paternal or maternal age-effect, they certainly do not exclude such influences. 
In regard to the findings presented here, it is proposed instead that the 'switching mechanism' converts $a_{r}+$ to $a_{r}-$ alleles in affected fathers. Its frequency increases with advancing age while the frequency of conversion of $a_{r}-$ to $a_{r}+$ alleles increases with advancing age of affected mothers. This would imply that a somatic gene-mutation occurred in one, but not in the other, twin described by Oepen (1973).

A feature of the theory of autoaggressive disease (Burch, 1968) is that the rate of somatic genemutation in central growth-control stem cells is effectively constant from an early age. The linear regressions observed in Fig. 2 accord with the idea that a single somatic mutation initiates the change that leads, through an autoaggressive attack, to allelic conversion in germ cells. It may not be coincidental that the moduli of the two slopes are virtually indistinguishable; a test of equality yielded $\mathbf{F}=0.95$ with $1,4 \mathrm{df} ; \mathrm{P}>0.3$. This would mean that the average rate of conversion of $a_{r+}$ to $a_{r}-$ alleles in male germ cells is balanced by the average rate of conversion of $a_{r}-$ to $a_{r}+$ alleles in female germ cells. The estimate obtained for this switching frequency is $0.850 \pm 0.024 \%$ rigid cases per year of parental age.

Regardless of whether this explanation is correct, the results show why persons of early onset frequently have affected fathers. Below a parental age of 35 years, and hence in the majority of instances, Fig. 2 indicates that offspring bearing the
Huntington gene who are born to affected fathers will become rigid cases of the disease more often than those born to affected mothers. It has previously been shown that such cases have an earlier mean onset age than choreic subjects and that the predominance of paternal cases of early onset is an extrapolation from adulthood of a general effect (Brackenridge, 1973).

This work was supported by a grant from the National Health and Medical Research Council of Australia. Appreciation is expressed to Professor P. R. J. Burch for helpful comments on the manuscript.

\section{REFERENCES}

Bittenbender, J. A and Quadfasel, F. A. (1962). Rigid and akinetic forms of Huntington's chorea. Archives of Neurology, 7, 275-288. Brackenridge, C. J. (1972a). A statistical study of half-sibships born to parents affected with Huntington's disease. Fournal of Medical Genetics, 9, 17-22.

Brackenridge, C. J. (1972b). Familial correlations for age at onset and age at death in Huntington's disease. Fournal of Medical Genetics, 9, 23-32.

Brackenridge, C. J. (1972c). The relation of some features of Huntington's disease to the age at onset of symptoms in parents. Clinical Genetics, 3, 477-482.

Brackenridge, C. J. (1973). The relation of sex of affected parent to the age at onset of Huntington's disease. Fournal of Medical Genetics, 10, 333-336.

Burch, P. R. J. (1968). An Inquiry Concerning Growth, Disease and Ageing. Oliver and Boyd, Edinburgh.

Burch, P. R. J. (1973). Genetic and pathogenetic implications of the age-incidence of Huntington's chorea. Advances in Neurology, 1, 179-190.

Byers, R. K. and Dodge, J. A. (1967). Huntington's chorea in children. Report of four cases. Neurology, 17, 587-596.

Jones, M. B. (1973). Fertility and age of onset in Huntington's chorea. Advances in Neurology, 1, 171-177.

Oepen, H. (1973). Discordant features of monozygotic twin sisters with Huntington's chorea. Advances in Neurology, 1, 199-201. 